\title{
FTO is ... twee handen op één buik Een reis begint met de eerste stap
}

\author{
S. Pans, namens MSFU “Sams" en U.P.S.V. "Unitas Pharmaceuticorum”, A. de Boer, T.B. Voorn, \\ T.H.C. Damen
}

\section{Samenvatting}

Samenwerking tussen artsen en apothekers komt de farmaceutische behandeling van patiënten ten goede. In de praktijk weten deze beroepsgroepen vaak niet genoeg van elkaars werk. Farmacotherapeutisch overleg (FTO) tussen apothekers en artsen kan de samenwerking bevorderen. Een goede basis voor deze samenwerking kan al gelegd worden door gezamenlijk onderwijs voor farmaciestudenten en geneeskundestudenten.

Sinds kort kunnen farmacie- en geneeskundestudenten in Utrecht een gezamenlijk keuzevak volgen. Hierin is onder andere onderwijs over FTO opgenomen. Gebleken is dat geneeskunde- en farmaciestudenten niet goed weten wat dat inhoudt. Dat de studenten wel geinteresseerd zijn in elkaars vakgebied bleek op de FTO-dag die door geneeskunde-en farmaciestudenten in Utrecht gezamenlijk is georganiseerd. Uit een vragenlijst die studenten op deze dag konden invullen over de rol van arts en apotheek ten aanzien van farmacotherapie bleek dat de opvattingen over elkaars inbreng en verantwoordelijkheid uiteenliepen. Er was wel sterke overeenstemming over de wenselijkheid van samenwerking. Tijdens de FTO-dag discussieerden de studenten in gemengde groepjes over casus waarin een probleem aan de orde werd gesteld waarbij zowel de arts als de apotheek een rol speelt. De algemene indruk van de dag was dat er van beide kanten een grote bereidheid is om meer over elkaar te leren en zo de samenwerking te verbeteren. Gezamenlijke activiteiten zoals een FTO-dag en het Utrechtse keuzeonderwijs zijn een eerste stap in deze richting. (Pans S, namens MSFU "Sams" en U.P.S.V. "Unitas Pharmaceuticorum", Boer A de, Voorn TB, Damen THC. FTO is ... twee handen op één buik. Een reis begint met de eerste stap. Tijdschrift voor Medisch Onderwijs 2003;22(1):5-9.)

\section{Inleiding}

De apotheker als zorgverlener is nog geen beeld dat op het netvlies staat van de arts, de politiek, de bevolking. Helaas, want de optimale driehoeksverhouding tussen arts, apotheker en patiënt kan een recept zijn voor optimale zorg. De politiek heeft niet altijd een hoge dunk van apothekers. $\mathrm{Zij}$ vindt dat "een koopman met zijn bonussen en kortingen" geen zorgverlener kan zijn.

Niet alleen de politiek denkt zo over apothekers. Ook artsen, die gedurende hun opleiding weinig leren over geneesmiddelen en hun werking en best een collega kunnen gebruiken die hen helpt de kwaliteit van de farmacotherapie te verbeteren, hebben soms een verkeerd begrip van de kennis en kunde van apothekers. Helaas wordt in de discussie over het functioneren van de apotheker vaak vergeten dat de artsenijbereidkunst een belangrijke bijdrage kan leveren aan kostenbesparing in de gezondheidszorg.

Een manier om misvattingen die artsen en apothekers over elkaar hebben weg te nemen, is wellicht het verbeteren van de samenwerking. Jong geleerd is oud gedaan, dus waarom hier niet al in de opleiding mee beginnen? In Utrecht is kort 
geleden een eerste stap in deze richting gezet. Studenten van de geneeskunde- en farmacieopleidingen krijgen de kans om te leren 'samenwerken'. Tot nu toe kwamen studenten van beide faculteiten niet eerder met elkaar in aanraking dan in de beroepspraktijk. Geen wonder dat er onbegrip heerst, ook tussen studenten. "Multicultureel onderwijs", die naam gaf de (huidige) Commissie Opleidingscontinuüm aan de samenwerking in het curriculum. De toenmalige minister van Volksgezondheid, Welzijn en Sport, mevrouw Borst, deed de uitspraak dat dit type onderwijs bijdraagt aan de 'efficiëntie' van de productie van goede zorgverleners.

\section{Onderwijs voor artsen en apothekers}

Gemeenschappelijk onderwijs voor artsen en apothekers is een onderwerp met een lange geschiedenis. Al in 1986 was er aandacht voor de ontwikkeling hiervan. ${ }^{1}$ In september 2002 is een belangrijke stap gezet op weg naar de verwezenlijking van het ideaal. Aan de Universiteit Utrecht werd voor het eerst een keuzevak aangeboden dat door zowel farmacie- als geneeskundestudenten gevolgd kan worden. Het keuzevak zal onder andere het onderwerp Farmaco Therapie Overleg (FTO) gaan behandelen. Het is hoognodig dat dit onderwerp aan de orde komt. Uit ervaring is gebleken dat de afkorting FTO voor veel geneeskundestudenten een onbekend begrip is. Farmaciestudenten weten meestal nog wel wat de afkorting betekent, maar ook bij hen is weinig bekend over hoe een FTO in zijn werk gaat in de praktijk.

Dit gegeven heeft gevolgen voor de praktijk. Apothekers en huisartsen komen een aantal maal per jaar bij elkaar in een FTO. Daar er in de opleiding nauwelijks aandacht wordt besteed aan FTO en gezien het ontbreken van een eenduidige richtlijn voor de manier waarop een FTO zou moeten plaatsvinden, kan de manier waarop het overleg gevoerd wordt, van regio tot regio sterk verschillen. En het verschil in uitvoering gaat gepaard met een verschil in 'kwaliteit'. Er zijn groepen waar een hoogwaardig FTO plaatsvindt, maar er zijn ook samenwerkingsverbanden waar het FTO nog veel te wensen overlaat. $^{2}$

\section{FTO-dag}

Dat studenten aanvoelen dat er behoefte is aan een betere samenwerking, blijkt uit het feit dat Groningse farmacie- en geneeskundestudenten vorig jaar voor het eerst een FTO-dag voor studenten farmacie en geneeskunde organiseerden.

Dit voorbeeld vond dit jaar navolging in Utrecht. De Utrechtse farmaceutische studentenvereniging "Unitas Pharmaceuticorum" (U.P.) en de medische faculteitsvereniging Utrecht "Sams" namen het initiatief tot de eerste FTO-dag voor studenten in Utrecht. De studenten werden bij de organisatie begeleid door professor De Boer, hoogleraar farmacotherapie aan de Faculteit Farmaceutische Wetenschappen te Utrecht, en professor Voorn, hoogleraar huisartsgeneeskunde aan het Universitair Medisch Centrum Utrecht. Professor De Boer is een van de initiatiefnemers van het keuzevak FTO in Utrecht en professor Voorn heeft veel ervaring met het werken in FTO-groepen.

\section{Opiniepeiling}

Een van de interessante elementen van deze studiedag was een opiniepeiling onder de studenten over zaken waarover in de praktijk de meningen verdeeld zijn. De vragen, die de studenten met eens of oneens konden beantwoorden, staan in tabel 1 .

Een arts heeft relatief weinig farmacotherapeutische kennis, maar moet de 
huisarts na het stellen van de diagnose dan ook de keuze van het geneesmiddel aan de apotheker overlaten? Twee derde van de farmaciestudenten was het hiermee eens. Echter, bijna 94\% van de geneeskundestudenten zat er niet op te wachten dat het voorschrijven hun uit handen werd genomen. Er zijn plannen om in de Wet op de geneeskundige behandelingsovereenkomst (WGBO) op te nemen dat de apotheker medebehandelaar is en derhalve intensief bij de behandeling van patiënten betrokken moet worden. Wat is de reactie van de studenten hierop? De mening van de farmaciestudenten was eenduidig: $100 \%$ was het met de stelling eens. Zorgwekkender is de mening van de geneeskundestudenten: $62.5 \%$ was het er niet mee eens dat een apotheker als medebehandelaar mag op- treden. Daarentegen vond $81 \%$ van de geneeskundestudenten (tegen $95 \%$ van de farmaciestudenten) niet dat de apotheek overbodig is en dat degene die de diagnose stelt dan de medicatie bewaakt. Op de vraag of FTO nodig is voor een goede afstemming van het farmacotherapiebeleid van apothekers en artsen antwoordde $80 \%$ van de geneeskundestudenten (tegen $100 \%$ van de farmaceuten) het hiermee eens te zijn.

\section{Groepsdiscussie}

Apothekers en artsen zijn, zoals eerder vermeld, vaak onwetend over elkaars kennis. Dit onbegrip begint al tijdens de studie. Een geneeskundestudent dacht dat "een apotheker niet zo goed zou zijn in de omgang met een patiënt en dat zijn voornaamste bezigheid het schuiven van

Tabel 1. Mening van de studenten over de vragen uit de opiniepeiling. Elke vraag kon alleen met eens of oneens beantwoord worden.

\begin{tabular}{lll}
\hline & \multicolumn{1}{c}{ EENS } \\
\cline { 2 - 3 } $\begin{array}{l}\text { Geneeskunde } \\
\text { Vragen }\end{array}$ & $\begin{array}{l}\text { Farmacie } \\
\text { studenten } \\
\mathrm{N}=\mathbf{2 0}\end{array}$ & $\mathrm{N}=\mathbf{2 5}$ \\
\hline $\begin{array}{l}\text { De huisarts heeft onvoldoende kennis over farmacotherapie om verant- } \\
\text { woord geneesmiddelen voor te kunnen schrijven. Nadat de huisarts de } \\
\text { diagnose heeft gesteld, dient de apotheker de keuze van een genees- } \\
\text { middel voor zijn rekening te nemen. }\end{array}$ & $6.25 \%$ & $70 \%$ \\
$\begin{array}{l}\text { De apotheker is medebehandelaar en moet derhalve intensief bij de } \\
\text { behandeling van patiënten betrokken worden. }\end{array}$ & $37.50 \%$ & $100 \%$ \\
$\begin{array}{l}\text { De apotheek kan worden afgeschaft. Alle geneesmiddelen zijn goed ver- } \\
\text { pakt en kunnen dus op een drogistachtige wijze worden verstrekt. Medi- } \\
\text { catiebewaking moet worden gedaan door degene die de diagnose stelt. }\end{array}$ & $18.75 \%$ & $5.26 \%$ \\
$\begin{array}{l}\text { De (huis)arts moet de reden van voorschrijven op enigerlei wijze } \\
\text { kenbaar maken. }\end{array}$ & $50 \%$ & $100 \%$ \\
$\begin{array}{l}\text { Tijdens de geneeskunde- en farmacieopleiding moet meer aandacht } \\
\text { worden besteed aan de samenwerking tussen artsen en apotheker. }\end{array}$ & $100 \%$ & $100 \%$ \\
$\begin{array}{l}\text { FTO is noodzakelijk om het beleid van (huis)arts en apotheker op elkaar } \\
\text { af te stemmen en zodoende de zorg voor de patiënt te optimaliseren. }\end{array}$ & $80 \%$ & $100 \%$ \\
\hline
\end{tabular}


doosjes is, zonder dat daar toegevoegde waarde aan gegeven is". Farmaciestudenten daarentegen voelden aan dat "een arts de capaciteiten van een apotheker onderschat". Verder vonden zij dat een arts "wat weinig flexibel is in voorschrijfgedrag en dat de farmacotherapeutische kennis beneden de maat is".

Een van de doelstellingen die de organisatie met de studenten-FTO-dag wilde bereiken is het verminderen van dit onbegrip. Om deze doelstelling te verwezenlijken moesten de studenten in contact komen met de kennis van de andere partij. In 'gemengde' groepjes van tien gingen de studenten met elkaar in discussie over maatschappelijke onderwerpen. In de eerste casus kregen de studenten de opdracht tot een eenduidig beleid te komen over euthanasie. De richtlijnen die algemeen gelden, werden ter beschikking gesteld. De discussie werd begeleid door artsen en apothekers, die hun visie konden geven vanuit de praktijk. Een van de zaken die als opmerkelijk beschouwd werden, was dat 'de arts' opgenomen was in de euthanasierichtlijnen voor apothekers, maar dat 'de apotheker' niet opgenomen was in de richtlijnen voor artsen.

In een tweede casus werd kennisgemaakt met de heer Z. Pil en zijn medicatiehistorie. Aan de hand hiervan moesten de studenten erachter komen waarvoor meneer Pil de verscheidene medicamenten voorgeschreven kreeg en welke wijzigingen in de medicatie raadzaam waren. Deze opdracht bleek niet zo eenvoudig te zijn. Pas nadat de werkelijke indicatie aan het licht kwam, bleek dat er fouten in de medicatie waren geslopen.

Door de studenten op deze manier in contact te laten komen met patiëntengegevens werd geprobeerd erachter te komen hoe zij er tegenover stonden dat de reden van voorschrijven op enigerlei wijze kenbaar gemaakt wordt aan de medicatiebewaker. Tijdens een plenair gedeelte was over dit onderwerp al een stelling gepresenteerd: 'De apotheker moet inzicht krijgen in de reden waarom een bepaald geneesmiddel wordt voorgeschreven'. 50\% van de geneeskundestudenten was het hiermee eens, tegen $100 \%$ van de farmaciestudenten. Opvallend is dat er over dit onderwerp vele discussies gevoerd worden in de praktijk en dat daar de meningen over dit onderwerp zeer verdeeld zijn. ${ }^{3}$

\section{Reacties van deelnemers}

Naast het verminderen van onbegrip hoopte de organisatie van de FTO-dag een indruk te kunnen geven over hoe FTO er aan toe gaat in de praktijk. Bij aanvang van de dag gaven de deelnemende studenten aan dat dit in hun verwachting lag. Verder gaven de deelnemers aan dat ze "benieuwd waren of apothekers en artsen verschillend denken en of er met deze verschillen toch overeenstemming over een probleem zou kunnen komen". Een geneeskundestudent liet weten te willen leren “wat zo'n apotheker voor een toegevoegde waarde heeft bij de behandeling van een patiënt", een opstelling met een open blik. In ieder geval was $100 \%$ van alle aanwezigen het er over eens dat meer aandacht moet worden besteed aan de samenwerking tussen artsen en apothekers in opleiding.

Ter illustratie volgen hieronder nog enkele reacties van deelnemers na afloop van de studiedag:

Martine Janssen (Farmacie): "Geneeskundestudenten bleken geen flauw idee te hebben van wat een apotheker nu eigenlijk de hele dag doet. De FTO-dag heeft de vooroordelen enigszins weg kunnen nemen". Maarten ten Berg (Farmacie): "Het was een groot succes, waardevol om eens met 
geneeskundestudenten van gedachten te wisselen"

Marie-Elise Wiesman (Geneeskunde): "Het was een erg interactieve dag met een zeer creatieve opzet. Zeker voor herhaling vatbaar. Ik weet nu beter waar een apotheker zich mee bezighoudt."

Een student die niet aanwezig kon zijn: "Ik hoop dat docenten de waarde van dit soort evenementen meer in gaan zien en studenten stimuleren tot deelname. Het had mij een interessante dag geleken."

\section{Ten slotte}

De organisatie van de studenten-FTO-dag hoopt dat de weg is geopend om in een vroeg stadium farmacie- en geneeskundestudenten in contact te laten komen met elkaars kennis en kunde, iets dat uiteindelijk de farmaceutische patiëntenzorg ten goede zal komen. Zij denkt in deze opzet geslaagd te zijn. Een lange reis begint immers bij de eerste stap.

\section{Literatuur}

1. Blom AThG, Gier JJ, Glerum JH, Luttik A, Pans FMJ, Willemsen K. Gezamenlijk onderwijs voor aanstaande huisartsen en aanstaande apothekers. Pharmaceutisch Weekblad 1986;121:184-7.

2. Eijk MEC. Effects of outreach strategies on quality of pharmacotherapy. Utrecht: Thesis; 2001.

3. Porsius AJ. Apothekers artsen prescriptie. Pharmaceutisch Weekblad 2002;137:298-9.

De auteurs:

S.J.A.. Pans, studente farmacie en e.t. praeses der Utrechtse Pharmaceutische Studentenvereniging "Unitas Pharmaceuticorum".

Prof. dr. A. de Boer, hoogleraar farmacotherapie aan de Faculteit Farmaceutische Wetenschappen te Utrecht.

Prof. dr. T.B. Voorn, hoogleraar huisartsgeneeskunde aan het Universitair Medisch Centrum Utrecht.

T.H.C. Damen, student geneeskunde en ex-praeses der Medische Studenten Faculteitsvereniging Utrecht "Sams".

Correspondentieadres:

S. Pans, Mgr. Van de Weteringstraat 124, 3581 EN

Utrecht,solangepans@hotmail.com.

\section{Summary}

Patients benefit when doctors and pharmacists achieve good collaboration in the provision of their treatment. In practice the two professions often do not know a great deal about each other's professional practice. In the Netherlands groups of GPs and pharmacists hold so-called Pharmaco Therapy Meetings (PTM) to promote co-operation. A solid basis for collaboration could already be laid by multidisciplinary courses for medical and pharmacology students during undergraduate training.

Recently a joint elective for medical and pharmacology students was introduced in Utrecht. Among other subjects attention is paid to PTM. There is evidence that the two groups of students do not have a very clear idea of what those meetings entail. Students are interested in each other's profession, however. This became clear during the PTM day which was recently organised by pharmacy and medical students in Utrecht. On the PTM day students were surveyed about the roles of pharmacists and doctors in pharmacotherapy. The responses demonstrated dramatic differences of opinion between the two groups about their respective contribution and responsibilities. However, there was general agreement among students about the desirability of collaboration. During the PTM day students met in mixed groups to discuss cases consisting of problems which involved both doctors and pharmacists. The overriding impression from the PTM day was that both sides are eager to learn more about each other's professions in order to improve collaboration. Joint initiatives like the PTM day and multidisciplinary education appear to be well received by the students. (Pans $S$ for the Associations of Pharmacology and Medical Students, Boer A de, Voorn TB, Damen THC. PTM means joining forces. Collaboration starts with education. Dutch Journal of Medical Education 2003;22(1):5-9.) 